\title{
Goma Xantana: \\ características e condições operacionais de produção
}

\author{
Xanthan Gum: \\ characteristics and operational conditions of production
}

\author{
Caroline Dellinghausen Borges ${ }^{1}$; Claire Tondo Vendruscolo ${ }^{2}$
}

\section{Resumo}

Goma xantana é um polissacarídeo extracelular produzido pelas bactérias do gênero Xanthomonas. Sua funcionalidade é uma conseqüência direta de sua estrutura química. Esta estrutura tem sido amplamente estudada por ser passível de mudanças, sendo dependente do microrganismo produtor e das condições operacionais aplicadas durante a fermentação. O trabalho tem como objetivo revisar a influência das condições operacionais de produção de xantana nas características físico-químicas da goma produzida. Palavras-chave: Xantana. Condições operacionais. Composição química. Reologia.

\begin{abstract}
Xanthan gum is an extracelullar polysaccharide produced by bacteria of the genus Xanthomonas. Its functionality is a direct consequence of its chemical structure. This structure has been widely studied because it is subject to changes, dependant on the producer microrganism and on the operational conditions applied during the fermentation. The purpose of this paper is to review the influence of the operational conditions of xanthan production in the physiochemical characteristics of the gum produced.
\end{abstract}

Key words: Xanthan. Operational conditions. Chemical composition. Reology.

\section{Introdução}

A goma xantana é um polissacarídeo produzido por espécies de bactérias do gênero Xanthomonas (SUTHERLAND, 1993). Sua produção, comercialização e utilização como espessante e estabilizante tornou-se crescente com o passar dos anos. Estima-se uma produção mundial de 50.000ton/ano consumidas entre outras, pelas indústrias de alimentos, farmacêutica, produtos agrícolas e de petróleo (ROSALAM; ENGLAND, 2006).
Grande parte da literatura referente à produção de xantana está baseada em cepas obtidas de coleções de cultura, principalmente Xanthomonas campestris pv campestris NRRL B-1459 e seus derivados (SOUW; DEMAIN, 1980; JANA; GHOSH, 1995; AMANULLAH et al., 1996; YOO; HARCUM, 1999; GARCÍA-OCHOA; CASTRO; SANTOS, 2000; LÓPEZ et al., 2004). Porém, o isolamento de microrganismos a partir de recursos naturais é uma importante ferramenta na busca de cepas que apresentem alta produção de xantana com qualidade

1 Doutoranda em Biotecnologia Agrícola. Centro de Biotecnologia - Universidade Federal de Pelotas, Pelotas, RS, Brasil, caroldellin@bol.com.br.

2 Docente do Departamento de Ciências dos Alimentos e Centro de Biotecnologia - Universidade Federal de Pelotas, Pelotas, RS, Brasil, claire@ufpel.tche.br. 
reológica (TORRESTIANA; FUCIKOVSKY; GALINDO, 1990; NITSCHKE; THOMAS, 1995; GUPTE; KAMAT, 1997; ANTUNES et al., 2003).

Estudos de produção de xantana por diferentes espécies, patovares e cepas da bactéria Xanthomonas em diferentes condições operacionais de agitação, aeração, pH, temperatura, meios de cultivo, etc, tem sido realizados evidenciando a diferença nas características físico-químicas dos diferentes polímeros produzidos (LILLY; WILSON; LEACH, 1958; MOCHI; SCAMPARINI, 1994; SÁNCHEZ et al., 1997; ANTUNES et al., 2003).

No Brasil, a totalidade das gomas xantanas utilizadas pelos diferentes segmentos industriais são importadas. No entanto, como o país é o maior produtor dos insumos básicos para produção de xantana, que são o açúcar e o álcool, é viável a produção nacional de xantana. Dessa forma, estudos de seleção de cepas e de condições operacionais de produção são necessários na busca de produtos que possam competir com os atualmente comercializados. O trabalho tem como objetivo revisar a influência das condições operacionais de produção de xantana nas características físicoquímicas da goma produzida.

\section{Xantana}

A goma xantana foi descoberta em 1950, por pesquisadores do Northern Regional Research Laboratory(NRRL), do DepartamentodeAgricultura dos Estados Unidos. O objetivo daquele estudo era identificar microrganismos que produzissem gomas de interesse comercial solúveis em água (BORN; LANGENDORFF; BOULENGUER, 2002). O polissacarídeo B-1459, ou goma xantana, produzido pela bactéria Xanthomonas campestris pv campestris NRRL B-1459 foi extensamente estudado por apresentar propriedades espessantes e estabilizantes. A partir de 1960, pesquisas foram realizadas em alguns laboratórios industriais, culminando na produção semi-comercial da goma Kelzan pela empresa Kelco (Estados Unidos)
(GARCÍA-OCHOA et al., 2000) e, em 1964, a produção comercial do polímero para propósito industrial tornou-se viável, para a aplicação em produtos não alimentícios (HARDING; CLEARY; IELPI, 1994). Em 1969, a goma xantana foi aprovada pelo FDA (Food and Drug Administration) para uso como estabilizante, emulsificante e espessante em alimentos (ROCKS, 1971).

Dentre as empresas mais expressivas no mercado de produção de xantana, salientam-se a Merck e Cargill (Estados Unidos), Danisco (Dinamarca) e Jungbunzlauer (Austria). Do volume total de xantana produzida no mundo, $65 \%$ é utilizado na indústria de alimentos, $15 \%$ na indústria de petróleo e ao redor de $20 \%$ em aplicações diversas. A demanda vem aumentando e estima-se um crescimento anual de 5-10\% (ROSALAM; ENGLAND, 2006).

O Brasil é importador desta goma, entretanto, há expectativa que num futuro próximo, duas plantas de produção de xantana entrem em funcionamento. A produção e a aplicação de xantana têm sido extensamente estudadas por diversos grupos de pesquisadores de universidades brasileiras. Estes estudos já resultaram em nove depósitos de patente no Instituto Nacional de Propriedade Industrial; dentre estes, quatro patentes são relacionadas ao processo de produção (INSTITUTO NACIONAL DA PROPRIEDADE INDUSTRIAL, 2007).

\section{Estrutura}

A xantana, produzida pela bactéria Xanthomonas campestris, apresenta-se com uma estrutura primária composta de repetidas unidades pentassacarídicas. É constituída, normalmente, de unidades de $\beta$-Dglicose unidas por ligação 1-4, formando a cadeia principal celulósica; na posição C(3) de cada resíduo de glucose alternada existe uma cadeia lateral trissacarídica contendo unidades de $\beta$-D-manose1,4- $\beta$-D-ácido glicurônico- 1,2- $\alpha$-D-manose, podendo apresentar na posição $\mathrm{C}(6)$ da $\alpha$-D-manose interna grupos $\mathrm{O}$-acetil e na $\beta$-D-manose terminal substituinte 4,6-ácido pirúvico (JANSSON; 
KENNE; LINDBERG, 1975; SLONEKER; JEANES, 1962). O ácido acético no polissacarídeo B-1459 parece estar presente como um éster e o ácido pirúvico está condensado como um acetal com unidades de manose terminal (JANSSON; KENNE; LINDBERG, 1975).

A localização de grupos adicionais de acetil na molécula de xantana é incerta, mas múltiplas acetilações são possíveis (SHATWELL et al., 1990). A xantana produzida por algumas cepas, especialmente de Xanthomonas oryzae, apresentam dois grupos acetil no resíduo de manose interna (SUTHERLAND, 1993). Stankowski, Mueller e Zeller (1993) ao analisarem uma xantana, encontraram o segundo resíduo de acetil na manose externa não piruvatada.

A molécula de xantana é perfeitamente regular quanto à presença de ramificações em uma glicose $\mathrm{a}$ cada duas, no entanto, há uma certa irregularidade, pois nem todas as cadeias laterais são acetiladas ou piruvatadas. Freqüentemente, não está piruvatada mais que uma cadeia de cada duas, mas essa proporção varia em função da cepa utilizada e das condições de cultivo (LINDEN; LORIENT, 1996).

A estrutura secundária da xantana depende das condições sob as quais a molécula é caracterizada. A molécula pode estar em uma conformação ordenada ou desordenada. Dois modelos têm sido propostos para a estrutura secundária da molécula de xantana: simples e dupla hélice A conformação ordenada pode ser nativa ou renaturada; não há consenso quanto à existência de relação entre a natividade da conformação e o tipo de estrutura verificada. A forma nativa está presente em temperaturas abaixo do ponto de transição conformacional da molécula, que depende da força iônica do meio em que a xantana produzida está dissolvida. A transição conformacional ordem-desordem é dirigida pela ocorrência de temperaturas acima do ponto de transição e/ou a redução da força iônica. Tanto a manutenção da conformação nativa (ordenada), quanto a renaturada (re-ordenada) dependem dos mesmos fatores (BORN; LANGENDORFF; BOULENGUER, 2002).

Em condições de baixa força iônica, a repulsão entre os grupos carboxílicos tende a desestabilizar a estrutura ordenada, mas, se sais são adicionados, os cátions estabilizam a conformação evitando o rompimento induzido por aquecimento (HOLZWARTH, 1976). Este autor demonstrou que a temperatura de transição de mudança conformacional aumenta em função da concentração de $\mathrm{Na}^{+}$e $\mathrm{Ca}^{2+}$.

A função dos substituintes na temperatura de transição foi investigada por Dentini, Crescenzi e Blasi (1984); Callet, Milas e Rinaudo (1987) e Shatwell et al. (1990). De acordo com seus resultados, a remoção dos grupos acetil diminui a temperatura de transição, mas a depiruvatação resulta em aumento desta. Assim o substituinte acetil apresenta um efeito estabilizante da forma ordenada da xantana, entretanto, os resíduos de piruvato apresentam efeito oposto.

\section{Composição química}

A composição química da xantana tem sido amplamente estudada, por se tratar de uma estrutura passível de mudanças ocasionadas pelas diferentes condições operacionais aplicadas durante a fermentação, como também pelo microrganismo produtor.

Os polissacarídeos extracelulares produzidos por bactérias Xanthomonas têm sido amplamente caracterizados. Primeiramente, o polímero produzido pela bactéria Xanthomonas phaseoli foi analisado, sendo composto de D-glucose, D-manose e D-ácido glucurônico na proporção de 1:1:1 (LESLEY; HOCHSTER, 1959). Após este trabalho, Sloneker e Jeanes (1962) estudaram o polissacarídeo produzido pela bactéria Xanthomonas campestris cepa NRRL B-1459, e verificaram que este é composto de D-glucose, D-manose e D-ácido glucurônico na proporção 2,8:3,0:2,0; além de ácido acético e ácido pirúvico, na proporção $1,73: 0,627$. 
Vários trabalhos sucederam-se, mostrando a influência da espécie, patovar e cepa na composição química qualitativa e quantitativa do polímero, conforme será relatado a seguir. $\mathrm{O}$ polissacarídeo xantana, produzido por diferentes espécies de Xanthomonas, contém normalmente glucose, manose e ácido glucurônico, exceto Xanthomonas vesicatoria, que contém galactose em substituição à manose(ORENTAS; SLONEKER; JEANES, 1963). Entretanto, a ocorrência de outros monossacarídeos tem sido relatada. A presença de galactose, juntamente de ribose, por exemplo, foi descrita no polissacarídeo produzido por cepas mutantes de Xanthomonas campestris lac ${ }^{+}$(KONICEK; LASÍK; WURST, 1977). Para Lowson e Symes (1977) e Souza e Vendruscolo (1999), o patovar pode determinar a composição do polissacarídeo. Esses autores relataram a presença de ramnose nos polímeros produzidos pelos patovares juglandis e pruni, respectivamente.

A literatura tem mostrado que variações quantitativas entre polímeros produzidos por diferentes microrganismos do gênero Xanthomona, são mais comuns que diferenças qualitativas. As principais variações são relativas ao conteúdo dos ácidos pirúvico e acético. O conteúdo de ácido pirúvico no polissacarídeo de diferentes espécies e cepas de Xanthomonas foi avaliado, inicialmente, por Orentas, Sloneker e Jeanes (1963). Os resultados entre as espécies variaram de $1,05 \%$ a 7,64\%. Uma pequena variação no conteúdo de ácido pirúvico foi observada nos polissacarídeos de diferentes cepas da mesma espécie de Xanthomonas; os resultados para espécie phaseoli oscilaram entre 6,26 a 6,88\%. A composição química de duas xantanas, uma com alto teor de piruvato (HPXan) e outra com baixo (LPXAn), produzidas por Xanthomonas campestris, foi relatada por Sandford et al. (1977). A primeira apresentou $4,4 \%$ de piruvato, enquanto a segunda 2,5\% de piruvato; a concentração dos demais constituintes foi similar. A diferença entre as concentrações de piruvato e acetil em polímeros produzidos por diferentes patovares e cepas de Xanthomonas campestris também foi evidenciada por Shatwell, Sutherland e Ross-Murphy (1990). Seus resultados são mostrados na Tabela 1.

Tabela 1. Composição química de polímeros produzidos por diferentes cepas e patovares de Xanthomonas campestris.

\begin{tabular}{lccccc}
\hline Microrganismo & Glc (\%) & Man (\%) & Aglc (\%) & Ac (\%) & Ap (\%) \\
\hline X. campestris pv campestris 646 & 40,2 & 36,0 & 23,8 & 4,5 & 4,4 \\
X. campestris pv phaseoli 1128 & 40,3 & 36,7 & 23,0 & 7,7 & 1,7 \\
X. campestris pv oryzae PXO $_{61}$ & 40,6 & 37,7 & 21,7 & 14,3 & 0,3 \\
X. campestris pv phaseoli 556 & 40,5 & 38,7 & 20,8 & 1,6 & 6,0 \\
\hline
\end{tabular}

Glc $=$ glucose, Man = manose, Aglc = ácido glucurônico, Ac = ácido acético e Ap = ácido pirúvico.

O conteúdo de piruvato e acetil do polímero produzido por três isolados de Xanthomonas campestris e uma variante da coleção de cepas Xanthomonas campestris NRRL B-1459 (E2) foi determinado por Sánchez et al. (1997). Segundo estes autores, um baixo conteúdo de piruvato foi encontrado nos polímeros produzidos pelos isolados 10 e $11,(0,24$ e $0,50 \%$, respectivamente), entretanto, estes polímeros apresentaram alta concentração de acetil (10 e 8,1\%, rsepectivamente). Já o isolado 16 apresentou $6,82 \%$ de piruvato e $4,6 \%$ de acetil, e a variante E2, 2,56\% de piruvato e 7,3\% de acetil.

Valores de até $5 \%$ de acetil e $8,1 \%$ de piruvato são possíveis teoricamente, assumindo um grupo acetil por cadeia lateral, mas a proporção de grupos acetil algumas vezes excede este valor (SHATWELL et al., 1990). 


\section{Características reológicas}

Reologia é a ciência que estuda a deformação da matéria, ou ainda, o estudo da mobilidade dos fluidos (SHAW, 1975; MACHADO, 2002). Existem duas maneiras gerais de estudar aspectos reológicos: a primeira consiste em desenvolver expressões matemáticas, que possam descrever os fenômenos reológicos sem fazer maiores referências a suas causas, e a segunda consiste em correlacionar o comportamento mecânico observado com a estrutura detalhada do material em questão (SHAW, 1975). Por meio da análise reológica, ou seja, de análises de viscosidade e viscoelasticidade, têm-se um indicador da qualidade do polímero (AMANULLAH et al. 1996; MARCOTTE; HOSHAHILI; RAMASWAMY, 2001).

A xantana é solúvel em água fria ou quente, exibindo alta viscosidade até mesmo em baixas concentrações (ROCKS, 1971; JEANES, 1974). Soluções de xantana são altamente pseudoplásticas, ou seja, a viscosidade diminui com o aumento da taxa de deformação, mas recuperam rapidamente a viscosidade na remoção da tensão de cisalhamento, logo o fenômeno da histerese não é pronunciado (ROCKS, 1971). A associação das cadeias de xantana existe quando em repouso ou em baixas taxas de cisalhamento, sendo estabilizadas pelas ligações de hidrogênio (CUVELIER; LAUNAY, 1986). No cisalhamento, a extensão da agregação é reduzida pelo alinhamento das cadeias, resultando em uma baixa viscosidade (KATZBAUER, 1998).

A viscosidade das soluções de xantana é muito estável em termos de variações no $\mathrm{pH}$, temperatura e força iônica (ROCKS, 1971). A viscosidade destas soluções não é fortemente afetada pela mudança de pH entre 1-2 a 11-13 (GARCÍA-OCHOA et al., 2000; BORN; LANGENDORFF; BOULENGUER, 2002). Entretanto, segundo Challen (1994), a estabilidade das soluções frente às mudanças de $\mathrm{pH}$ é dependente da concentração da goma. À concentração de $1 \%$ de goma, não existe mudança na viscosidade na faixa de $\mathrm{pH} 1,5$ a 11 ; a $0,25 \%$ de goma a estabilidade é menor e a viscosidade máxima é alcançada entre pH 6 e 8.

De uma forma geral, na literatura é citado que as soluções de goma xantana, comparativamente a outros polímeros, são resistentes à degradação pelo calor, mantêm-se a elevadas temperaturas por prolongados períodos de tempo, sem nenhuma grande alteração de viscosidade. Somente uma pequena mudança é observada quando soluções são autoclavadas a $121^{\circ} \mathrm{C}$ por 15 a 30 minutos. Soluções de xantana são também estáveis sob condições de frio (ROCKS, 1971). Para Challen (1994), o efeito da temperatura na viscosidade das soluções também é dependente da concentração da goma.

A presença de sais melhora a resistência da goma à degradação pelo calor e pode causar alterações no comportamento reológico. Em baixas concentrações de xantana, a adição de traços de sais pode causar uma leve queda de viscosidade (ROCKS, 1971; SWORN, 2000). Entretanto, em altas concentrações de polissacarídeos, os sais incrementam a viscosidade marcadamente (JEANES; PITTSLEY; SENTI, 1961; ROCKS, 1971; SWORN, 2000). De acordo com Kang e Pettit (1993), a viscosidade das soluções de xantana é independente da concentração de sais quando o conteúdo de sais exceder $0,1 \%$ $(\mathrm{m} / \mathrm{v})$.

As cadeias de xantana, em solução, formam uma rede tridimensional contínua, com fraca ligação; conseqüentemente, estas soluções podem também ser caracterizadas como géis fracos. A associação intermolecular, por meio das cargas negativas da molécula de xantana, pode ser promovida por íons metálicos; a ordem da efetividade na indução de géis fracos é $\mathrm{Ca}^{2+}>\mathrm{K}^{+}>\mathrm{Na}^{+}$. Entretanto, sob certas condições, a xantana pode gelificar. Isso pode ocorrer na presença de certos íons trivalentes $\left(\mathrm{Cr}^{3+}, \mathrm{Al}^{3+}\right.$ ou $\left.\mathrm{Fe}^{3+}\right)$, ou com o efeito sinérgico com outros polímeros (BORN; LANGENDORFF; BOULENGUER, 2002). A goma xantana formará géis termorreversíveis, quando misturados com galactomananas como goma locusta ou goma tara. 
Misturada com goma guar, resulta em um aumento de viscosidade. A distinção entre aumento da viscosidade ou gelatinização parece depender da proporção entre manose: galactose da galactomanana e da distribuição da galactose na cadeia lateral (MORRIS, 1995).

\section{Influência da composição química da Xantana nas características reológicas}

O comportamento reológico é dependente da composição química do polímero. Entretanto, não há unanimidade entre os pesquisadores quanto à influência de cada constituinte. Segundo Sandford et al. (1977), o conteúdo de piruvato pode ser usado como um indicador da qualidade reológica. Assim, xantanas com alto conteúdo de piruvato $(>4 \%)$ apresentam viscosidade superior àquelas com conteúdo inferior de piruvato $(0,5$ a 3\%). Para Smith et al. (1981), amostras com alto teor de piruvato aumentam a viscosidade das soluções de xantana na presença de $\mathrm{KCl}$ pelo aumento na associação macromolecular. Seus resultados indicam que o substituinte piruvato promove associação e formação da macroestrutura pelo aumento na afinidade polímero-polímero, comparativamente à afinidade polímero-solvente. Lechner, Gehke e Nordmeler (1996) propuseram uma teoria semelhante relacionada à concentração de xantana ao conteúdo de piruvato. Segundo esses autores, o aumento na extensão da associação das moléculas de xantana na presença de alto conteúdo de piruvato pode fornecer uma explicação para o aumento atípico na viscosidade observada durante a fermentação, na qual altos níveis de produção são acumulados.

Entretanto, segundo Candia e Deckwer (1999), uma grande quantidade de produto acumulado não assegura forte interação molecular quando os pontos de contato estão diminuídos. Um alto grau de piruvatação pode levar à situação onde grupos de segmentos de moléculas de polímeros vizinhos interajam fortemente. Já para Kennedy, Jones e Barker (1982); Callet, Milas e Rinaudo (1987); Torrestiana, Fucikovsky e Galindo (1990) e Torres et al. (1993), a variação no conteúdo de ácido pirúvico não pôde ser correlacionada com a variação nas propriedades reológicas. Dessa forma, ainda não há consenso do efeito do conteúdo de piruvato nas propriedades reológicas das soluções de xantana.

Alguns estudos de modificação química abordam a relação entre composição química e reologia. Xantanas com diferentes teores de acetil e piruvato podem ser obtidas por modificação genética do microrganismo produtor; ou ainda por modificação química do produto final (TAYLOR; NASR-ELDIN, 1993).

A remoção do grupo acetil produz polissacarídeo com melhores propriedades físicas; a viscosidade dos polímeros com baixo teor de acetil, na presença de sais, é significativamente maior, produzindo filmes fortes e flexíveis (SLONEKER; JEANES, 1962). De acordo com Tako e Nakamura (1984), a xantana desacetilada apresenta maior viscosidade em altas concentrações, quando comparada a xantana nativa. Este fenômeno foi atribuido à formação de associação intermolecular mais intensa devido a desacetilação. $\mathrm{Na}$ desacetilação, o incremento de viscosidade depende das condições utilizadas e também do grau de acetil removido (PINTO, 2005). A alteração na viscosidade, causada pela desacetilação, pode ser mais ou menos intensa. Bradshaw et al. (1983), por exemplo, relataram um pequeno efeito na viscosidade das soluções de polímeros depiruvatados e desacetilados.

Além da influência do conteúdo de piruvato e acetato nas propriedades reológicas da xantana, outros constituintes parecem também exercer alguma influência. Biopolímeros que, aparentemente, continham maior quantidade de manose e ácido glucurônico apresentaram maior grau espessante (ANTUNES et al., 2000). Moreira et al. (2001) relataram que o aumento na concentração de manose mantém ou aumenta a viscosidade das soluções 
de xantana frente ao aquecimento; polímeros com alta concentração de glucose apresentam um efeito oposto.

A composição química não influencia apenas a viscosidade, mas também as propriedades viscoelásticas. $\mathrm{O}$ efeito da presença de piruvato na interação macromolecular aumentou a capacidade gelificante da xantana, quando combinada com outros polímeros. Xantanas com alto grau de piruvatação formam um gel altamente termoresistente, enquanto xantanas depiruvatadas ou naturalmente livres de piruvato reduzem a interação depreciando a formação do gel (LECHNER; GEHKE; NORDMELER, 1996).

\section{Massa molar}

Uma ampla faixa de valores propostos para a massa molar da xantana $\left(1,1\right.$ e 47 x $10^{6} \mathrm{~g}$ $\mathrm{mol}^{-1}$ ) tem resultado da aplicação de diferentes técnicas, tais como: cromatografia de exclusão por tamanho, espalhamento de luz e viscosidade intrínsica (SUTHERLAND, 1996). A determinação acurada da massa molar é difícil por algumas razões, incluindo: alta massa molar, rigidez da molécula e pela tendência do polissacarídeo formar agregados em solução (BORN; LANGENDORFF; BOULENGUER, 2002).

A alta massa molar da goma e sua estrutura terciária conferem à sua solução a propriedade de tornar-se muito viscosa, apresentando propriedades reológicas de interesse comercial (GALINDO, 1994). A massa molar da xantana pode ser influenciada pelo microrganismo produtor e pelas condições operacionais aplicadas durante a fermentação. Casas, Santos e García-Ochoa (2000) relatam a existência de vários trabalhos acerca da influência das condições operacionais na estrutura molecular e na massa molar da xantana. Os mesmos autores ressaltam que não há concordância nas conclusões obtidas nos diferentes trabalhos, porque, geralmente, apenas uma única variável é estudada.
O aumento da velocidade de agitação empregada durante a fermentação, segundo Peters et al. (1989), influenciou a massa molar da xantana, alcançando $6,9 \times 10^{6} \mathrm{~g} \mathrm{~mol}^{-1}$ em $200 \mathrm{rpm}$ e $8,6 \times 10^{6} \mathrm{~g} \mathrm{~mol}^{-1}$ em $800 \mathrm{rpm}$. Entretanto, Papagianni et al. (2001) não conseguiram correlacionar a massa molar da xantana com a velocidade de agitação utilizada durante a fermentação, obtendo $5 \times 10^{5} \mathrm{~g} \mathrm{~mol}^{-1}$.

A temperatura empregada durante a fermentação também influenciou a massa molar da xantana, segundo Casas, Santos e García-Ochoa (2000). Os resultados mostraram que o aumento da temperatura de $25{ }^{\circ} \mathrm{C}$ para $34{ }^{\circ} \mathrm{C}$ reduziu a massa molar do polímero.

A influência do patovar de Xanthomonas campestris nos resultados de massa molar foi avaliada por Shatwell, Sutherland e Ross-Murphy (1990). Seus resultados mostraram que a massa molar variou de $0,9 \times 10^{6} \mathrm{~g} \mathrm{~mol}^{-1}$, para o polímero produzido pelo patovar campestris (646), a 1,27 x $10^{6} \mathrm{~g} \mathrm{~mol}^{-1}$ para o patovar phaseoli (1128), quando analisado pela técnica de espalhamento de luz. Pela técnica de viscosidade intrínseca, a massa molar variou $2,4 \times 10^{6} \mathrm{~g} \mathrm{~mol}^{-1}$ a $6,3 \times 10^{6} \mathrm{~g} \mathrm{~mol}^{-1}$, respectivamente.

A relação entre o conteúdo de piruvato e acetil com a massa molar do polímero foi determinada por Callet, Milas e Rinaudo (1987). Os resultados de massa molar foram de 5,2 x $10^{6} \mathrm{~g} \mathrm{~mol}^{-1}$ para xantana nativa; 5,2 × $10^{6} \mathrm{~g} \mathrm{~mol}^{-1}$ para xantana desacetilada; $4,3 \times 10^{6} \mathrm{~g} \mathrm{~mol}^{-1}$ para xantana livre de piruvato e $2,3 \times 10^{6} \mathrm{~g} \mathrm{~mol}^{-1}$ para a xantana livre de acetil e piruvato. Estes resultados mostram que a hidrólise do grupo piruvato provocou uma hidrólise parcial dos resíduos de acetil e conseqüentemente degradação do polímero, entretanto, a desacetilação não afetou o conteúdo de ácido pirúvico e a massa molar da xantana.

\section{Microrganismo}

Diferentes trabalhos têm mostrado que a produção e a viscosidade da xantana é dependente 
do microrganismo utilizado. Algumas espécies de Xanthomonas foram avaliadas para produção de xantana por Lilly, Wilson e Leach (1958). A maior produção ocorreu por Xanthomonas campestris $(9,9$ $\left.\mathrm{g} \mathrm{L}^{-1}\right)$ e a menor por Xanthomonas papavericola (1,8 $\left.\mathrm{g} \mathrm{L}^{-1}\right)$. Das espécies testadas, Xanthomonas phaseoli, Xanthomonas campestris e Xanthomonas malvacearum foram as que apresentaram maior produção do polissacarídeo. Seis isolados de Xanthomonas campestris foram estudados quanto à produção de xantana por Torrestiana, Fucikovsky e Galindo (1990). Destes seis isolados, dois não produziram polímero na condição testada e o isolado SI alcançou a maior produção, $8,0 \mathrm{~g} \mathrm{~L}^{-1}$. No trabalho de Nitschke e Thomas (1995), com cepas selvagens de Xanthomonas campestris, obteve-se, como menor produção, $10,6 \mathrm{~g} \mathrm{~L}^{-1}$ para a cepa $\mathrm{C} 5$ e, como maior produção, 14,5 $\mathrm{g} \mathrm{L}^{-1}$ para a cepa Cv2C8. Diferentes patovares e cepas de Xanthomonas campetris foram avaliadas quanto à produção de xantana por Sánchez et al. (1997). Para o patovar campestris, a produção oscilou entre 0,0 e 15,3 g $\mathrm{L}^{-1}$, a produção pelo patovar juglandis variou entre 0,0 a $7,3 \mathrm{~g} \mathrm{~L}^{-1}$ e pelos patovares pruni e manihotis a produção alcançou 7,4 e 9,0 $\mathrm{g} \mathrm{L}^{-1}$, respectivamente.

Diversas cepas do patovar pruni de Xanthomonas campestris foram avaliadas quanto à produção de xantana. Moreira et al. (2001) avaliaram dezoito cepas deste patovar. $\mathrm{O}$ valor mínimo de produção obtido neste estudo foi de $2,3 \mathrm{~g} \mathrm{~L}^{-1}$ para a cepa 44 e máximo de $8,4 \mathrm{~g} \mathrm{~L}^{-1}$ para a cepa 73 . Outras trinta cepas do mesmo patovar foram avaliadas quanto à produção e viscosidade do polímero por Borges (2004). Em seu trabalho, os resultados de produção variaram entre $3,6 \mathrm{~g} \mathrm{~L}^{-1}$ para a cepa 51 e 9,2 $\mathrm{g} \mathrm{L}^{-1}$ para a cepa 83; e a viscosidade de $1.370 \mathrm{mPa}$.s para o polímero produzido pela cepa 83 a $12.700 \mathrm{mPa} . \mathrm{s}$ para o polímero da cepa 101. Antunes et al. (2003) também avaliaram a produção pelo patovar pruni e a viscosidade do polímero. Das treze cepas avaliadas pelos autores, a cepa 06 apresentou o menor valor de produção 4,1 $\mathrm{g} \mathrm{L}^{-1}$ e a maior viscosidade 15.000 mPa.s. Já a cepa 31 apresentou a maior produção obtendo 26,4 $\mathrm{g} \mathrm{L}^{-1}$ e a menor viscosidade, 125 $\mathrm{mPa}$.s. Estes relatos corroboram a importância do microrganismo na produção e viscosidade da xantana.

\section{Condições operacionais de produção}

Todos os parâmetros passiveis de mudança em um processo fermentativo são considerados condições operacionais, tais como: temperatura, aeração, agitação, pH, etc. A otimização destas condições para produção de xantana é particularmente importante, considerando sua ampla aplicação industrial (DE VUYST; VERMEIRE, 1994). Na escala de bancada, tendo em vista sua maior flexibilidade e menor custo de operação, os dados básicos sobre o processo devem ser levantados dentro do maior nível de pormenorização possível. Nesta escala, devem ser realizadas as tarefas básicas, como a seleção do microrganismo e o estudo das condições operacionais (BANDINO JÚNIOR; SCHMIDELL, 2001).

Uma vez que se tenha acumulado suficiente experiência sobre o processo fermentativo em questão, e desde que se tenha atingido desempenho adequado do ponto de vista econômico, amplia-se a escala para um reator piloto. Como a operação é mais onerosa, deve-se reduzir o número de variáveis. Por fim, a escala industrial, devido à própria dimensão, visa ao lado econômico do processo, ou seja, a produção em grande escala. Nesta escala, procurase operar o fermentador sob condições similares àquelas ajustadas na escala piloto. Entretanto, o grande problema do aumento de escala está exatamente em reproduzir, na escala industrial, as condições responsáveis pelo bom desempenho do sistema, obtidas nas escalas de bancada e piloto. Deve-se atentar que, com a ampliação da escala de trabalho, perde-se a condição de reator homogêneo, freqüentemente observado na escala de bancada (BANDINO JÚNIOR; SCHMIDELL, 2001).

As condições operacionais, como a configuração do bioreator, modo de operação (batelada ou 
contínuo), composição do meio, temperatura, $\mathrm{pH}$, velocidade de agitação, taxa de aeração e o tempo de fermentação influenciam não apenas no crescimento do microrganismo e na produção de xantana, mas também na estrutura e características reológicas do polímero (KENNEDY; JONES; BARKER, 1982; BAIG; AHMAD, 1995; GUPTE; KAMAT, 1997; CASAS; SANTOS; GARCÍA-OCHOA, 2000; MOREIRA et al., 2001; ANTUNES et al., 2003). Dessa forma, a otimização das condições de fermentação na escala de bancada é extremamente necessária antes da ampliação da escala de produção.

\section{Agitação e aeração}

A agitação e a aeração são parâmetros necessários para evitar condições de anaerobiose decorrentes da alta viscosidade do meio pela formação do polissacarídeo, visto que a bactéria é estritamente aeróbia. Logo, a combinação adequada, para os níveis destes parâmetros, deve ser estudada para evitar a limitação na transferência de oxigênio ou condições de estresse hidrodinâmico (SUTHERLAND, 1993; CASAS; SANTOS; GARCÍA-OCHOA, 2000). Em sistemas não-newtonianos, como na fermentação para produção de xantana, a agitação é mais significativa para a transferência de oxigênio do que a aeração (CASAS; SANTOS; GARCÍA-OCHOA, 2000; RICHARD; MARGARITIS, 2002). Grande parte da literatura estuda diferentes condições de aeração alterando a velocidade de agitação, entre outros autores, pode-se citar Peters et al. (1989); Lorda, Pastor e Balatti (1995); Casas, Santos e García-Ochoa (2000); Papagianni et al. (2001).

Os microrganismos conseguem manter um bom desempenho e, quando cultivados em baixas concentrações de oxigênio dissolvido, são muito interessantes do ponto de vista econômico. A manutenção de altas concentrações de oxigênio dissolvido demanda um maior consumo de energia, em virtude de uma maior agitação e aeração (SCHMIDELL, 2001).
Diversos trabalhos mostram a relação entre velocidade de agitação e taxa de aeração com o crescimento celular, produção, composição química e características reológicas da xantana. A influência da taxa de aeração na viscosidade e no conteúdo de ácido pirúvico da xantana foi estudada por Cadmus et al. (1978). Para esses autores, as maiores viscosidades e o conteúdo máximo de piruvato foram alcançados pela utilização de 0,75 vvm e 1,5 vvm. A produção e viscosidade da xantana sintetizada utilizando duas combinações de velocidade de agitação e taxa de aeração (250 rpm - 1,5 vvm e 350 rpm - $2 \mathrm{vvm}$ ) foram avaliadas por Moreira (2002). Em seu trabalho, a maior produção foi alcançada na condição de maior aeração, diferentemente da viscosidade, que foi mais elevada com taxas mais baixas de aeração.

A produção de xantana em diferentes velocidades de agitação (200, 400, 600 e 800 rpm) foi avaliada por Peters et al. (1989), utilizando uma aeração de 0,33 vvm. Os resultados mostraram que a limitação de oxigênio foi possivelmente a causa da baixa produção $\left(6,3 \mathrm{~g} \mathrm{~L}^{-1}\right)$ em 200rpm, entretanto, com a aplicação de 800rpm a maior produção foi alcançada $\left(16,4 \mathrm{~g} \mathrm{~L}^{-1}\right)$. Casas, Santos e GarcíaOchoa (2000) também avaliaram a produção de xantana em diferentes velocidades de agitação (100, 300, 500 e $800 \mathrm{rpm})$, com aeração de 1 vvm. Segundo estes autores, o crescimento de biomassa e a produção de xantana alcançaram um máximo com velocidade de agitação fixada em $500 \mathrm{rpm}$. Na velocidade de agitação de 800 rpm, ambos, biomassa e produção de xantana foram baixos, provavelmente devido ao dano provocado às células pelo estresse hidrodinâmico. Da mesma forma, Papagianni et al. (2001) testaram diferentes velocidades de agitação (100, 200, 300, 400 e $600 \mathrm{rpm})$, utilizando 1 vvm. Em seu trabalho, o aumento dos níveis de agitação resultou no aumento dos níveis de produção. Além disso, o conteúdo de piruvato das xantanas produzidas aumentou com o aumento da velocidade de agitação. Para esses autores, o efeito benéfico do aumento da agitação foi atribuído à redução da viscosidade 
do meio, aumentando a transferência de nutrientes e oxigênio necessários para formação de xantana. Após avaliar diferentes trabalhos da literatura pôdese concluir que o estresse hidrodinâmico, além de ser dependente da agitação/aeração, parece também ser dependente do microrganismo.

\section{Meios de cultivo}

O conhecimento das necessidades nutricionais de uma linhagem é estudo de vital importância, objetivando o fornecimento dos nutrientes apenas necessários, por questões econômicas do processo produtivo. Algumas características também devem ser consideradas, como: não provocar problemas na recuperação do produto, não causar dificuldades no tratamento final do efluente, ter composição razoavelmente fixa e os componentes devem ser estáveis, permitindo armazenamento prolongado (SCHMIDELL, 2001).

Geralmente, classificam-se os meios de cultivo como químico definido e complexo. Meio químico definido é o meio cuja composição química é qualitativa e quantitativamente conhecida, podendo ser reproduzida a qualquer instante (SCHMIDELL, 2001). Alternativamente, para suprir as necessidades de linhagens mais exigentes e, em geral, com características nutricionais mal conhecidas, podese adicionar certos materiais complexos. Estes são chamados de meios complexos, sendo compostos de nutrientes como extrato de levedura, de carne ou de planta ou de produtos de digestão protéica dessa ou de outras fontes (TORTORA; FUNKE; CASE, 2005). Esses materiais (individualmente ou adicionados conjuntamente) permitem introduzir no meio de cultura os fatores ausentes em um meio definido, mas, além de onerosos, são complexos e de composição variável ao longo do tempo de armazenagem. Também a dependência do fornecedor e qualidade variável dos lotes são fatores de restrição (SCHMIDELL, 2001).

Com relação aos meios mais complexos, e igualmente menos onerosos, pode-se mencionar o uso de matérias-primas naturais, tais como caldo de cana-de-açúcar, farinhas diversas (trigo, milho, soja, cevada), água de maceração de milho, etc. Como a composição química dependerá de uma série de fatores, tais como solo, variedade do vegetal, safra, clima, processamento e estocagem etc, freqüentemente é necessária a adição de alguns sais, particularmente contendo nitrogênio e fósforo. Esses fatos indicam que podem ocorrer oscilações no processo fermentativo que emprega essas matérias-primas, obrigando as empresas produtoras a manterem instalações piloto para o ajuste da composição do meio a cada novo lote de matériaprima que a empresa recebe (SCHMIDELL, 2001).

O meio padrão para produção de xantana deve conter fontes de nitrogênio, de carbono, íons fosfato e magnésio e alguns elementos traços, sendo atribuído o custo de 20 a $30 \%$ do processo total (BORN; LANGENDORFF; BOULENGUER, 2002). Diversos trabalhos mostram a relação entre meio de cultivo (definido, complexo e meio adicionado de matérias-primas naturais) com a produção de xantana, composição química e comportamento reológico. Dentre eles, alguns devem ser salientados, como o trabalho de Souw e Demain (1979) que realizaram um estudo nutricional de produção de xantana em meio químico definido, sendo testados como fonte de carbono: sacarose, frutose e xilose; fontes de ácidos orgânicos: piruvato, succinato e cetoglutarato e fontes de nitrogênio: aminoácidos, sais de amônio, nitrato de sódio e uréia. Diferentes fontes de nitrogênio (água de maceração de milho, farinha de soja, peptona, extrato de levedura e resíduos de destilarias) para produção de xantana sintetizada por Xanthomonas campestris IC19 e sua influência na viscosidade e composição química do polímero foram avaliados por Kennedy, Jones e Barker (1982). O efeito da fonte de carbono (glucose, sacarose, melaço e sirodex A - xarope de glicose) e fonte de nitrogênio (água de maceração de milho em substituição ao $\left.\left(\mathrm{NH}_{4}\right)_{2} \mathrm{HPO}_{4}\right)$ na produção e características físico-químicas da xantana produzida por Xathomonas campestris NRRL B-1459 foi 
relatado por De Vuyst e Vermeire (1994). Já Gupte e Kamat (1997) avaliaram a influência de diferentes fontes de carbono (glucose, sacarose, lactose e amido), nitrogênio (ausência, extrato de levedura, peptona, uréia, água de maceração de milho, $\left(\mathrm{NH}_{4}\right)_{2} \mathrm{SO}_{4}, \mathrm{NH}_{4} \mathrm{Cl}, \mathrm{NaNO}_{3}$ e extrato de levedura + peptona) e sais inorgânicos $\left(\mathrm{FeCl}_{3}\right.$, $\mathrm{NaCl}$, citrato, $\mathrm{MgSO}_{4} 7 \mathrm{H}_{2} \mathrm{O}, \mathrm{CaCO}_{3}, \mathrm{KH}_{2} \mathrm{PO}_{4}$, $\mathrm{K}_{2} \mathrm{HPO}_{4}$ ) na produção de xantana por Xanthomonas campestris ICa-125 e características reológicas da goma. Outros trabalhos de produção de xantana a partir de resíduos agroindustriais podem ser citados, como exemplo, a utilização de soro de leite (KONICEK; KONICKOVÁ-RADOCHOVÁ, 1992; ANTUNES et al., 2000; NITSCHKE; RODRIGUES; SCHINATTO, 2001), resíduos cítricos (GREEN; SHELY; BILANOVIC, 1994; BILANOVIC; SHELEF; GREEN, 1994), resíduo de polpa de beterraba (YOO; HARCUM, 1999), resíduos de azeitona (LÓPEZ; MORENO; RAMOSCOMENZANA, 2001), melado (KALOGIANNIS et al., 2003), resíduos agrícolas (MORENO et al. 1998).

\section{pH e temperatura}

Existe um valor ótimo de $\mathrm{pH}$ e de temperatura para o desenvolvimento do microrganismo e acúmulo do produto. No entanto, o controle preciso do $\mathrm{pH}$ e da temperatura apenas é possível em reatores de bancada. Em reatores de grande porte, poderá ocorrer uma certa heterogeneidade ao longo do reator; entretanto, o ideal seria que a célula mantivesse o seu desempenho, apesar de uma certa flutuação nos valores destas grandezas tomadas como exemplo (SCHMIDELL, 2001).

Alguns autores estudam a produção de xantana em pH não controlado (DE VUYST; VERMEIRE, 1994; PAPAGIANNI et al., 2001). Nesse caso, o $\mathrm{pH}$ do caldo pode decrescer do $\mathrm{pH}$ neutro até $\mathrm{pH}$ próximo a 5, pela presença de grupos ácidos na xantana (GARCIA-OCHOA et al., 2000), ou pode aumentar, dependendo da composição do meio e da cepa utilizada (DE VUYST; VERMEIRE, 1994; PAPAGIANNI et al., 2001). Entretanto, a maioria concorda que o controle do $\mathrm{pH}$ na faixa de 6 a 8, pela utilização de álcalis como $\mathrm{KOH}$, $\mathrm{NaOH}$ e $(\mathrm{NH})_{4} \mathrm{OH}$, é o melhor para produção de xantana (ESGALHADO; ROSEIRO; COLLAÇO, 1995; GUPTE; KAMAT, 1997; LIAKOPOULOUKYRIAKIDES et al., 1997; CASAS; SANTOS; GARCÍA-OCHOA, 2000).

A produção de xantana tem sido avaliada na faixa de temperatura de 20 a $38^{\circ} \mathrm{C}$ (CADMUS et al., 1978; GUPTE; KAMAT, 1997; CASAS; SANTOS; GARCÍA-OCHOA，2000; LEELA; SHARMA, 2000). A maioria dos autores estabeleceu $28{ }^{\circ} \mathrm{C}$ como temperatura ótima de produção de xantana.

A temperatura e o $\mathrm{pH}$ ótimos para o crescimento celular e produção de xantana foram determinados por Esgalhado, Roseiro e Collaço (1995). A faixa ótima para o crescimento de Xanthomonas campestris em cultivo de batelada foi $\mathrm{pH}$ entre 6,0 $-7,5$ e temperatura entre $25-27{ }^{\circ} \mathrm{C}$. Para maior produção de xantana e viscosidade do polímero, valores de $\mathrm{pH}$ entre 7,0 - 8,0 e temperatura entre 25 $-30^{\circ} \mathrm{C}$, foram determinados. Esta diferença entre faixa ótima de $\mathrm{pH}$ e temperatura para crescimento celular e produção de xantana pode ser uma importante informação a ser incluída na estratégia de fermentação.

\section{Influência das condições operacionais na composição química da Xantana}

Numerosos estudos têm mostrado que as condições operacionais aplicadas durante a fermentação podem causar alguma variação na composição química da xantana, principalmente no conteúdo de ácido pirúvico e acético. A influência da taxa de aeração $(0,25$ a $1,5 \mathrm{vvm})$ e temperatura $\left(20\right.$ a $\left.30{ }^{\circ} \mathrm{C}\right)$ no conteúdo de ácido piruvico da xantana foi estudada por Cadmus et al. (1978). Para esses autores, o conteúdo máximo de piruvato $(3,6 \%)$ foi alcançado pela utilização de 0,75 vvm. Quando a temperatura foi avaliada, a xantana 
produzida a $20{ }^{\circ} \mathrm{C}$ apresentou maior conteúdo de piruvato $(4,1 \%)$. Casas, Santos e García-Ochoa (2000) também verificaram dependência entre a temperatura utilizada durante a fermentação com o conteúdo de ácido pirúvico da xantana. Entretanto, seus resultados demonstraram que o maior conteúdo deste constituinte foi obtido quando a fermentação foi conduzida em $28{ }^{\circ} \mathrm{C}$, o mesmo ocorreu para o conteúdo de acetil.

A relação entre velocidade de agitação utilizada durante a fermentação e conteúdo de ácido pirúvico e acético da xantana foi avaliada por Casas, Santos e García-Ochoa (2000). Os resultados mostraram que a concentração de ácido acético aumentou quando a velocidade de agitação foi aumentada, alcançando valor máximo em $500 \mathrm{rpm}$. Porém, a concentração de piruvato não foi influenciada pelas diferentes velocidades de agitação, diferentemente dos resultados obtidos por Papagianni et al. (2001), em que foi observada uma certa dependência entre agitação e grau de piruvatação da xantana. De acordo com seus resultados, não houve diferença significativa no conteúdo de piruvato das xantanas produzidas em 300, 400 e $600 \mathrm{rpm}$ (variando de 3 a 3,49\%). O efeito tornou-se mais pronunciado ao comparar o conteúdo de piruvato da xantana produzida em $100 \mathrm{rpm}$ e $600 \mathrm{rpm}(1,54$ e 3,49\%, respectivamente).

A alta concentração de nitrogênio no meio de produção parece reduzir a concentração de piruvato da molécula de xantana. De acordo com os resultados obtidos por Candia e Deckwer (1999), quando um alto conteúdo de $\mathrm{NH}_{4} \mathrm{Cl}$ foi utilizado $\left(8,6 \mathrm{~g} \mathrm{~L}^{-1}\right)$, o nível de piruvatação foi baixo, ao redor $1,5 \%$. No entanto, quando utilizada uma concentração menor $\left(0,62 \mathrm{~g} \mathrm{~L}^{-1}\right)$, o grau de piruvatação máximo foi atingindo, 7,4\%. Casas, Santos e García-Ochoa (2000) também demonstraram que o aumento da concentração de nitrogênio $\left(\mathrm{NH}_{4} \mathrm{NO}_{3}\right)$ no meio de produção, diminui o conteúdo de ácido pirúvico na molécula de xantana. Já o conteúdo de acetato parece não ser influenciado pela concentração inicial de nitrogênio empregada.
Polissacarídeos formados durante os diferentes estágios de fermentação contêm aproximadamente a mesma quantidade de ácido pirúvico. Nos primeiros dois dias de fermentação, $50 \%$ do total do polissacarídeo é produzido (ORENTAS; SLONEKER; JEANES, 1963). Uma variação não significante no conteúdo de piruvato e acetil com o tempo de fermentação foi observada por Milas, Viehweg e Weiss (1990). Entretanto, uma forte influência do tempo no conteúdo destes substituintes foi verificada por Casas, Santos e García-Ochoa (2000).

\section{Influência das condições operacionais nas características reológicas}

As diferentes condições operacionais utilizadas durante a fermentação também podem influenciar o comportamento reológico do polímero. A influência da taxa de aeração $(0,25-1,5 \mathrm{vvm})$ nas características reológicas da xantana foi avaliada por Cadmus et al. (1978). Seus resultados mostraram que, durante a produção, o aumento da taxa de aeração durante a produção, aumenta a viscosidade da goma obtida. Os mesmos autores também avaliaram o emprego de diferentes temperaturas $\left(20,24,27\right.$ e $\left.30^{\circ} \mathrm{C}\right)$ para produção de xantana e sua influência na viscosidade do polímero. De acordo com seus resultados, quanto maior a temperatura utilizada durante a fermentação, maior a viscosidade alcançada. Resultados semelhantes foram obtidos por Gupte e Kamat (1997), que avaliaram a viscosidade da xantana produzida na faixa de temperatura de 25 a $38{ }^{\circ} \mathrm{C}$, obtendo os melhores resultados na temperatura de $32^{\circ} \mathrm{C}$. Entretanto, para Casas, Santos e García-Ochoa (2000), a viscosidade das soluções do polímero produzido em altas temperaturas (34 ${ }^{\circ} \mathrm{C}$ ) foi inferior àqueles produzidos em temperaturas mais baixas $\left(25,28\right.$ e $\left.31^{\circ} \mathrm{C}\right)$, a $25^{\circ} \mathrm{C}$ foi obtida a maior viscosidade.

A influência da velocidade de agitação aplicada durante a produção de xantana e sua relação com as propriedades reológicas do polímero produzido 
tem sido pouco relatada na literatura. Casas, Santos e García-Ochoa (2000) avaliaram as propriedades reológicas da xantana produzida em diferentes velocidades de agitação. Para esses autores, em baixas velocidades de agitação (100 e 300 rpm), ocorreu uma limitação de oxigênio e a altas velocidades de agitação (superiores a $500 \mathrm{rpm}$ ) ocorreu estresse hidrodinâmico, produzindo um decréscimo nos parâmetros reológicos.

O polímero produzido em diferentes valores de $\mathrm{pH}$ tem apresentado características reológicas diferenciadas; os valores propostos por diferentes autores para obtenção de polímeros com alta viscosidade estâo na faixa de $\mathrm{pH}$ de 6 a 8 (ESGALHADO; ROSEIRO; COLLAÇO, 1995; GUPTE; KAMAT, 1997).

Vários trabalhos com a utilização de diferentes meios de cultivo têm avaliado a viscosidade do polímero obtido (CADMUS et al., 1978; DE VUYST; VERNEIRE, 1994; GUPTE; KAMAT, 1997; CANDIA; DECKWER, 1999; SOUZA; VENDRUSCOLO, 1999; ANTUNES et al., 2000; NITSCHKE; RODRIGUES; SCHINATTO, 2001). Dentre elas, cabe salientar o estudo realizado por Gupte e Kamat (1997) que avaliaram diferentes fontes e concentrações de carbono (glucose, sacarose, lactose e amido), nitrogênio (ausência, extrato de levedura, peptona, uréia, água de maceração de milho (CSL), $\left(\mathrm{NH}_{4}\right)_{2} \mathrm{SO}_{4}, \mathrm{NH}_{4} \mathrm{Cl}, \mathrm{NaNO}_{3}$ e extrato de levedura + peptona) e sais inorgânicos $\left(\mathrm{FeCl}_{3}\right.$, $\mathrm{NaCl}$, citrato, $\mathrm{MgSO}_{4} 7 \mathrm{H}_{2} \mathrm{O}, \mathrm{CaCO}_{3}, \mathrm{KH}_{2} \mathrm{PO}_{4}$, $\mathrm{K}_{2} \mathrm{HPO}_{4}$ ) no meio de cultivo. Dentre as fontes de carbono testadas pelos autores acima, pela utilização de $50 \mathrm{~g} \mathrm{~L}^{-1}$ de sacarose, obteve-se a xantana com a maior viscosidade. Em relação à fonte de nitrogênio, a utilização de extrato de levedura + peptona, 3 e $5 \mathrm{~g} \mathrm{~L}^{-1}$, respectivamente, provocou um efeito sinérgico, e aumentou a viscosidade do polímero. Dentre os sais inorgânicos testados, $0,5 \mathrm{~g} \mathrm{~L}^{-1}$ foi a concentração selecionada na otimização do meio com $\mathrm{NaCl}, \mathrm{MgSO}_{4} 7 \mathrm{H}_{2} \mathrm{O}, \mathrm{CaCO}_{3}, \mathrm{KH}_{2} \mathrm{PO}_{4}$, para obtenção de um polímero de alta viscosidade.

\section{Conclusão}

As condições operacionais aplicadas na produção de xantana influenciam o rendimento, composição química e na qualidade do polímero e são dependentes do microrganismo produtor. Dessa forma, a otimização das condições de fermentação na escala de bancada são extremamente necessárias antes da ampliação da escala de produção, principalmente quando novas cepas são avaliadas, na busca de alto rendimento e qualidade reológica do polímero sintetizado.

\section{Agradecimentos}

O presente trabalho foi realizado com o apoio do Conselho Nacional de Desenvolvimento Científico e Tecnológico - CNPq - Brasil.

\section{Referências}

AMANULLAH, A.; SERRANO, L. C.; GALINDO, E.; NIENOW, A. W. Reproducibility of pilot scale xanthan fermentations. Biotechnology Progress, New York, v. 12, n. 4, p. 466-473, Jul./Aug. 1996.

ANTUNES, A. E. C.; MOREIRA, A. S.; VENDRUSCOLO, J. L.; VENDRUSCOLO, C. T. Síntese de biopolímero xantana em meios convencionais e alternativos: viscosidade $\mathrm{x}$ composição. Revista Brasileira de Agrociência, Pelotas, v. 6, n. 2, p. 123-125, 2000.

Screening of Xanthomonas campestris pv pruni strains according to their production of xanthan and its viscosity and chemical composition. Brazilian Journal of Food Technology, Campinas, v. 6, n. 2, p. 317-322, 2003.

BAIG, S.; AHMAD, H. S. Effect of agitator configuration and rotational speed on the production of extracellular polysaccharide by Xanthomonas curcubitae PCSIR B-52. Journal of Fermentation and Bioengineering, Osaka, v. 79, n. 6, p. 572-578, 1995.

BANDINO JÚNIOR, A. C.; SCHMIDELL, W. Variação de escala. In: SCHMIDELL, W.; LIMA, U. A.; AQUARONE, E.; BORZANI, W. Biotecnologia industrial. São Paulo: Edgard Blücher, 2001. v. 2, p. 333354. 
BILANOVIC, D.; SHELEF, G.; GREEN, M. Xanthan fermentation of citrus waste. Bioresource Technology, Essex, v. 48, n. 2, p. 169-172, 1994.

BORGES, C. D. Caracterização da goma xantana em função da cepa de Xanthomonas campestris pv pruni $e$ das condições operacionais. 2004. Dissertação. (Mestrado em Ciência e Tecnologia Agroindustrial) Faculdade de Agronomia Eliseu Maciel, Universidade Federal de Pelotas, Pelotas.

BORN, K.; LANGENDORFF, V.; BOULENGUER, P. Xanthan. In: STEINBÜCHEL, A.; VANDAMME, E. J.; DE BAETS, S. Biopolymers. Weinheim: Weley-VCH, 2002. v. 5, p. 259-291.

BRADSHAW, I. J.; NISBET, B. A.; KERR, M. H.; SUTHERLAND, I.W. Modified xanthan: its preparation and viscosity. Carbohydrate Polymers, Barking, v. 3, n. 1, p. 23-38, 1983.

CADMUS, M. C.; KNUTSON, C. A.; LAGODA, A. A.; PITTSLEY, J. E.; BURTON, K. A. Synthetic media for production of quality xanthan gum in 20 liter fermentors. Biotechnology and Bioengineering, New York, v. 20, n. 7, p. 1003 -1014, 1978.

CALLET, F.; MILAS, M.; RINAUDO, M. Influence of acetyl and pyruvate contents on rheological properties of xanthan in dilute solution. International Journal of Biological Macromolecules, Guildford, v. 9, n. 5, p. 291293, oct. 1987.

CANDIA, J. L. F.; DECKWER, W. D. Effect of the nitrogen source on pyruvate content and rheological properties of xanthan. Biotechnology Progress, New York, v. 15, n. 3, p. 446-452, mai-jun. 1999.

CASAS, J. A.; SANTOS, V. E.; GARCÍA-OCHOA, F. Xanthan gum production under several operacional conditions: molecular structure and rheological properties. Enzyme and Microbiology Technology, New York, v. 26, n. 2-4, p. 282-291, feb. 2000.

CHALLEN, I. A. Xanthan gum: a multifunctional stabiliser for food products. In: NISHINARI, K.; DOI, E. Food Hydrocolloids: structures, properties and functions. New York: Plenum Press, 1994. p. 135-139.

CUVELIER, G.; LAUNAY, B. Concentration regimes in xanthan gum solutions deduced from flow and viscoelastic properties. Carbohydrate Polymers, Barking, v. 6, n. 5, p. 321-333, 1986.

DE VUYST, L.; VERMEIRE,A. Use of industrial medium components for xanthan production by Xanthomonas campestris NRRL B-1459. Applied Microbiology and Biotechnology, Berlin, v. 42, n. 2-3, p. 187-191, nov. 1994.
DENTINI, M.; CRESCENZI, V.; BLASI, D. Conformational properties of xanthan derivatives in dilute aqueous solution. International Journal of Biological Macromolecules, Guildford, v. 6, n. 2, p. 93-98, 1984.

ESGAlHADO, M. E.; ROSEIRO, J. C.; COLlAÇO, M. T. A. Interactive effects of $\mathrm{pH}$ and temperature on cell growth and polymer production by Xanthomonas campestris. Process Biochemistry, London, v. 30, n. 7, p. 667-671, 1995.

GALINDO, E. Aspects of the process for xanthan production. Transactions of the Institution of Chemical Engineers, London, v. 72, part. C, p. 227-237, 1994.

GARCÍA-OCHOA, F.; CASTRO, V. E.; SANTOS, V.E. Oxygen transfer and uptake rates during xanthan gum production. Enzyme and Microbial Technology, New York, v. 27, n. 9, p. 680-690, 2000.

GARCÍA-OCHOA, F.; SANTOS, V.E.; CASAS, J. A.; GÓMEZ, E. Xanthan gum: production, recovery and properties. Biotechnology Advances, New York, v. 18, n. 7, p. 549-579, nov. 2000.

GREEN, M.; SHELEF, G.; BILANOVIC, D. The effect of various citrus waste fractions on xanthan fermentation. The Chemical Engineering Journal, Lausanne, v. 56, n. 1, p. B37-B41, Dec. 1994.

GUPTE, M. D.; KAMAT, M. Y. Isolation of wild Xanthomonas strains from agricultural produce, their characterization and potencial related to polysaccharide production. Folia Microbiologica, Praha, v. 42, n. 6, p. 621-628, 1997.

HARDING, N. E.; CLEARY, J. M.; IELPI, L. Genetics and Biochemistry of xanthan gum production by Xanthomonas campestris. In: HUI, Y. H. KHACHATOURIANS, G. G. Food biotechnology: microorganisms. New York: VCH Publisher, 1994. p. 495-514.

HOLZWARTH, G. Conformation of extracellular polysaccharideofXanthomonascampestris. Biochemistry, Washington, v. 15, n. 19, p. 4333-4339, 1976.

INSTITUTO NACIONAL DA PROPRIEDADE INDUSTRIAL. Disponível em: www.inpi.gov.br. Acesso em: dezembro de 2007.

JANA, A. K.; GHOSH, P. Xanthan biosynthesis in continuous culture: citric acid as an energy source. Journal of Fermentation and Bioengineering, Osaka, v. 80, n. 5, p. 485-491, 1995.

JANSSON, P. E.; KENNE, L.; LINDBERG, B. Structure of the exocellular polysaccharide from Xanthomonas campestris. Carbohydrate Research, Amsterdam, v. 45, n. 1, p. 275-285, Dec. 1975. 
JEANES, A. Extracellular microbial polysaccharides new hydrocolloids of interest to the food industry. Food Technology, Chicago, v. 28, n. 5, p. 34-40, 1974.

JEANES, A.; PITTSLEY, J. E.; SENTI, F. R. Polysaccharide B-1459: a new hydrocolloid polyeletrolyte produced from glucose by bacterial fermentation. Journal of Applied Polymer Science, New York, v. 5, n. 17, p. 519-526, 1961.

KALOGIANNIS, S.; IAKOVIDOU, G.; LIAKOPOULOU-KYRIAKIDES, M.; KYRIAKIDIS, D. A.; SKARACIS, G. N. Optimization of xanthan gum production by Xanthomonas campestris grown in molases. Process Biochemistry, London, v. 39, n. 2, p. 249-256, Oct. 2003.

KANG, K. S.; PETTIT, D. J. Xanthan, gellan, wellan and rhamsan. In: WHISTLER, R. I.; BEMILLER, J. N. Industrial gums. New York: Academic Press, 1993. p. 341-398.

KATZBAUER, B. Properties and applications of xanthan gum. Polymer Degradation and Stability, Essex, v. 59, n. 1-3, p. 81-84, 1998.

KENNEDY, J. F.; JONES, P.; BARKER, S. A. Factors affecting microbial growth and polysaccharide production during the fermentation of Xanthomonas campestris cultures. Enzyme Microbiology Technology, New York, v. 4, n. 1, p. 39-43, 1982.

KONICEK, J.; KONICKOVÁ-RADOCHOVÁ, M. Use of whey for production of exocellular polysaccharide by mutant strain of Xanthomonas campestris. Folia Microbiologica, Praha, v. 37, n. 2, p. 102-104, 1992.

KONICEK, J.; LASÍK, J.; WURST, M. Production and characteristies of the exocellular polysaccharide in mutant strains of Xanthomonas fuscans. Folia Microbiologica, Praha, v. 22, n. 1, p. 12-18, 1977.

LECHNER, M. D.; GEHRKE, K.; NORDMEIER, E. Makromolekulare Chemie. Berlin: Birkhäuser, 1996.

LEELA, J. K.; SHARMA, G. Studies on xanthan production from Xanthomonas campestris. Bioprocess Engineering, New York, v. 23, n. 6, p. 687-689, 2000.

LESLEY, S. M.; HOCHSTER, R. M. The extracellular polysaccharide of Xanthomonas phaseoli. Canadian Journal of Biochemistry and Physiology, Ottawa, v. 37, n. 4, p. 513-529, 1959.

LIAKOPOULOU-KYRIAKIDES, M.; TZANAKAKIS, E. S.; KIPARISSIDIS, C.; EKATERIANIADOU, L. V.; KYRIAKIDIS, D. A. Kinetics of xanthan gum production from whey by constructed strains of Xanthomonas campestris in bath fermentations. Chemical Engineering \& Technology, Weinheim, v. 20, n. 5, p. 354-360, 1997.
LILLY, V. G.; WILSON, H. A.; LEACH, J. G. Bacterial polysaccharides. Applied Microbiology, Washington, v. 6, n. 2, p. $105-108$, mar. 1958.

LINDEN, G.; LORIENT, D. Bioquimica agroindustrial - revalorizacion allimentaria de la produccion agricola. Espanha: Acríbia, 1996.

LÓPEZ, M. J.; MORENO, J.; RAMOS-COMENZANA, A. Xanthomonas campestris strain selection for xanthan production from olive mill wastewaters. Water Research, New York, v. 35, n. 7, p. 1828-1830, May. 2001.

LÓPEZ, M. J.; VARGAS-GARCÍA, M. C.; SUAREZESTRELLA, F.; MORENO, J. Properties of xanthan obtained from agricultural wastes acid hydrolysates. Journal of Food Engineering, Essex, v. 63, n. 1, p. 111115, 2004.

LORDA, C. S.; PASTOR, M. D.; BALATTI, A. P. Obtención de xantano a partir de Xanthomonas campestris B-1459 em fermentadores com agitación mecânica. Revista Argentina de Microbiologia, Buenos Aires, v. 27, p. 146-155, 1995.

LOWSON, C. J.; SYMES, K. C. Oligosaccharides produced by partial acetolysis of xanthan gum. Carbohydrate Research, Amsterdam, v.58, n. 2, p. 433438, 1977.

MACHADO, J. C. V. Reologia e Escoamento de fluídos - ênfase na indústria do petróleo. Rio de Janeiro: Interciência, 2002.

MARCOTTE, M.; HOSHAHILI, A. R. T.; RAMASWAMY, H. S. Rheological properties of selected hydrocolloids as a function of concentration and temperature. Food Research International, Barking, v. 34, n. 8, p. 695-703, 2001.

MILAS, M.; VIEHWEG, H.; WEISS, A. Structure and properties of xanthan versus fermentation time in an emulsion system. Carbohydrate Polymers, Barking, v. 13, n. 2, p. 119-131, 1990.

MOCHI, A. C.; SCAMPARINI, A. R. P. Xanthan gum production from brazilian strains. In: NISHINARI, K.; DOI, E. Food Hydrocolloids. New York: Plenum Press, 1994. p. 147-150.

MOREIRA, A. S.; VENDRUSCOLO, J. L. S.; GILTUNES, C.; VENDRUSCOLO, C. T. Screening among 18 novel strains of Xanthomonas campestris pv pruni. Food Hydrocolloids, Oxford, v. 15, n. 4-6, p. 469-474, jul./nov. 2001.

MOREIRA, A. S. Produção, caracterização e aplicação de biopolímero sintetizado por cepas de Xanthomonas campestris pv pruni. 2002. Tese. (Doutorado em Biotecnologia) - Centro de Biotecnologia, Universidade Federal de Pelotas, Pelotas. 
MORENO, J.; LÓPES, M.J.; VARGAS-GARCIA, C.; VÁZQUEZ, R. Use of agricultural wastes for xanthan production by Xanthomonas campestris. Journal of Industrial Microbiology and Biotechnology, Hampshire, v. 21, n. 4-5, p. 242-246, Oct./Nov. 1998.

MORRIS, V. J. Bacterial polysaccharides. In: STEPHEN, A. M. Food polysaccharide and their applications. New York: Basel Marcel Dekker, 1995. p. 341-375.

NITSCHKE, M.; RODRIGUES, V.; SCHINATTO, L. F. Formulação de meios de cultivo à base de soro de leite para produção de goma xantana por $X$. campestris $\mathrm{C}_{7} \mathrm{~L}^{\mathrm{L}}$. Ciência e Tecnologia de Alimentos, Campinas, v. 21, n. 1, p. 82-85, jan./abr. 2001.

NITSCHKE, M.; THOMAS, R. W. S. P. Xanthan gum production by wild-type isolates of Xanthomonas campestris. World Journal of Microbiology \& Biotechnology, Oxford, v. 11, n. 5, p. 502-504, Sep. 1995.

ORENTAS, D. G.; SLONEKER, J. H.; JEANES, A. Pyruvic acid content and constituent sugars of exocellular polysaccharides from different species of the genus Xanthomonas. Canadian Journal of Microbiology, Ottawa, v. 9, n. 3, p. 427-430, 1963.

PAPAGIANNI, M.; PSOMAS, S. K.; BATSILAS, L.; PARAS, S. V.; KYRIAKIDIS, D. A.; LIAKOPOULOUKYRIAKIDES, M. Xanthan production by Xanthomonas campestris in batch cultures. Process Biochemistry, London, v. 37, n. 1, p. 73-80, Sep. 2001.

PETERS, H.; HERBST, H.; HESSELINK, P.; LÜNSDORF, H.; SCHUMPE, A.; DECKWER, W. The influence of agitation rate on xanthan production by Xanthomonas campestris. Biotechnology and Bioengineering, New York, v. 34, n. 11, p. 1393-1397, Sep. 1989.

PINTO, E. P. Desacetilação de xantana: influência no comportamento reológico. 2005. Dissertação (Mestrado em Ciência e Tecnologia Agroindustrial) - Faculdade de Agronomia Eliseu Maciel, Universidade Federal de Pelotas, Pelotas.

RICHARD, A.; MARGARITIS, A. Production and mass transfer characteristics of non-newtonian biopolymers for biomedical applications. Critical Reviews in Biotechnology, Boca Raton, v. 44, n. 4, p. 355-374, 2002.

ROCKS, J. K. Xanthan gum. Food Technology, Chicago, v. 25, n. 5 , p. 476-483, 1971.

ROSALAM, S.; ENGLAND, R. Review of xanthan gum production from unmodified starches by Xanthomonas campestris sp. Enzyme and Microbial Technology, New York, v. 39, n. 2, p. 197-207, 2006.
SÁNCHEZ, A.; RAMÍREZ, M. E.; TORRES, L. G.; GALINDO, E. Characterization of xanthans from selected Xanthomonas strains cultivated under constant dissolved oxygen. World Journal of Microbiology \& Biotechnology, Oxford, v. 13, n. 4, p. 443-451, jul. 1997.

SANDFORD, P. A.; PITTSLEY, J. E.; KNUTSON, C. A.; WATSON, P. R.; CADMUS, M. C.; JEANES, A. Variation in Xanthomonas campestris NRRL B - 1459: characterization of xanthan products of differing pyruvic acid content. In: SANDFORD, P.A.; LASKIN, A. Extracellular microbial polysaccharides. Washington: American Chemical Society, 1977. p. $192-210$.

SCHMIDELL, W. Microrganismos e meios de cultura para utilização industrial. In: SCHMIDELL, W.; LIMA, U. de A.; AQUARONE, E.; BORZANI, W. Biotecnologia industrial. São Paulo: Edgard Blücher, 2001. v. 2, p. 5-18.

SHATWELL, K. P.; SUTHERLAND, I. W.; DEA, I. C.M.; ROSS-MURPHY, S. B. The influence of acetyl and pyruvate substituents on the helix-coil transition behavior of xanthan. Carbohydrate Research, Amsterdam, v. 206, n. 1, p. 87-103, Sep. 1990.

SHATWELL, K. P.; SUTHERLAND, I. W.; ROSSMURPHY, S. B. Influence of acetyl and pyruvate substituents on the solution properties of xanthan polysaccharide. International Journal of Biological Macromolecules, Guildford, v. 12, n. 2, p. 71-78, Apr. 1990.

SHAW, D. J. Introdução à química dos colóides e de superficies. São Paulo: Edgard Blucher, 1975.

SLONEKER, J. H.; JEANES, A. Exocellular bacterial polysaccharide from Xanthomonas campestris NRRL B - 1459. Canadian Journal of Chemistry, Ottawa, v. 40, n. 11, p. 2066-2071, 1962.

SMITH, I. H.; SYMES, K. C.; LAWSON, C. J.; MORRIS, E. R. Influence of the pyruvate of xanthan on macromolecular association in solution. International Journal of Biological Macromolecules, Guildford, v. 3, n. 2, p. 129-134, 1981.

SOUW, P.; DEMAIN, A. Nutritional studies on xanthan by Xanthomonas campestris NRRL B1459. Applied and Environmental Microbiology, Washington, v. 37, n. 6, p. 1186-1192, 1979.

SOUW, P.; DEMAIN, A. Role of citrate in xanthan production by Xanthomonas campestris. Journal of Fermentation Technology, Osaka, v. 58, n. 5, p. 411-416, 1980.

SOUZA, A. da S.; VENDRUSCOLO, C. T. Produção e caracterização dos biopolímeros sintetizados por Xanthomonas campestris pv pruni cepas 24 e 58. Ciência e Engenharia, Uberlândia, v. 8, n. 2, p. 115-123, 1999. 
STANKOWSKI, J. D.; MUELLER, B. E.; ZELLER, $\mathrm{S}$. G. Location of a second O-acetyl group in xanthan gum by the reductive-cleavage method. Carbohydrate Research, Amsterdam, v. 241, n. 17, p. 321-326, 1993.

SUTHERLAND, I. W. Microbial biopolymers from agricultural products: production and potencial. International Biodeterioration \& Biodegradation, Barking, v. 38, n. 3-4, p. 249-261, 1996.

SUTHERLAND, I. W. Xanthan. In: SWINGS, J. G.; CIVEROLO, E. L. Xanthomonas. London: Chapman \& Hall, 1993. p. 363-388.

SWORN, G. Xanthan gum. In: PHILlIPS, G. O.; WILLIAMS, P. A. Handbook of Hydrocolloids. New York: CRC Press, 2000. p. 103-116.

TAKO, M.; NAKAMURA, S. Rheological properties of deacetylated xanthan in aqueous-media. Agricultural And Biological Chemistry, Tokyo, v. 48, n.12, p. 29872993, 1984.
TAYLOR, K. C.; NASR-EL-DIN, H. A. Xanthan biopolymers: a review of methods for the cetermination of concentration and for the measurement of acetate and pyruvate content. Journal of Petroleum Science and Engineering, Amsterdam, v. 9, n. 4, p. 273-279, 1993.

TORRES, L.G.; BRITO, E.; GALINDO, E.; CHOPLIN, L. Viscous behavior of xanthan solutions from a variant strain of Xanthomonas campestris. Journal of Fermentation and Bioengineering, Osaka, v. 75, n. 1, p. 58-64, 1993.

TORRESTIANA, B.; FUCIKOVSKY, L.; GALINDO, E. Xanthan production by some Xanthomonas isolates. Letters in Applied Microbiology, Oxford, v. 10, n. 2, p. 81-83, 1990.

TORTORA, G. J.; FUNKE, B. R.; CASE, C. L. Microbiologia. 8. ed. Porto Alegre: Artmed, 2005.

YOO, S. D.; HARCUM, S. W. Xanthan gum production from waste sugar beet pulp. Bioresource Technology, Essex, v. 70, n. 1, p. 105-109, Oct. 1999. 
